\title{
May we practise endotracheal intubation on the newly dead?
}

\author{
Michael Ardagh Christchurch School of Medicine, New Zealand
}

\begin{abstract}
Endotracheal intubation (ETI) is a valuable procedure which must be learnt and practised, and performing ETI on cadavers is probably the best way to do this, although lesser alternatives do exist.

Performing ETI on a cadaver is viewed with a real and reasonable repugnance and if it is done without proper authorisation it might be illegal. Some form of consent is required. Presumed consent would preferably be governed by statute and should only occur if the community is well informed and therefore in a position of being able to decline. Currently neither statute nor adequate informing exists. Endotracheal intubation on the newly dead may be justifiable according to a Guttman scale if the patient has already consented to organ donation and if further research supports the relevance of the Guttman scale to this question. A "mandated choice" with prior individual consent as a matter of public policy is the best of these solutions, however until such a solution is in place we may not practise endotracheal intubation on the newly dead.
\end{abstract}

\section{Introduction}

Endotracheal intubation, (ETI) is the placing of a tube in a patient's trachea and it is the preferred method of managing the airway in patients with life- threatening conditions. ${ }^{12}$ Adequate performance of endotracheal intubation requires the acquisition of knowledge and skills and the maintenance of expertise requires regular performance of the technique after it has been learned. Failure of the technique resulting in inadvertent intubation of the oesophagus is difficult to detect in the resuscitation milieu and will result in the patient's death if not rapidly corrected. ${ }^{3}$

Physicians have practied ETI on the newly dead for many years ${ }^{4}$ and despite suggestions that it is unlawful and unethical ${ }^{4}$ many still consider that there is no better way to maintain the necessary expertise. ${ }^{567-10}$ Surveys of emergency departments

\section{Key words}

Resuscitation; consent emergency medical services; cadaver; teaching materials; education; medical; teaching. in the United States of America and Australia suggest that one third to one half of emergency departments practise ETI on cadavers. ${ }^{11} 121314$

In 1988 Orlowski and colleagues published a paper supporting the practice of ETI on the newly dead and they consider this paper to be the first salvo in this debate. ${ }^{15}$ In 1992 the Norwegian Medical Association ruled that the practice should be abandoned. ${ }^{16}$ The British Medical Association and the Royal College of Nursing issued a joint statement condemning the practice in the United Kingdom, ${ }^{17}$ although they suggested that practising ETI on cadavers with facial injuries was justifiable due to its educational value, so long as family consent was obtained, and that other intubation practice should occur in the anaesthetic room, on the living. In the New York Times, December 15, 1994 an article appeared under the headline "Hospitals use bodies of dead for practice", but it failed to ignite significant debate in the public media. ${ }^{18}$

This paper will examine this practice under the headings: The argument for; About the body; and About consent, and then some possible future directions will be presented.

\section{The argument for}

Endotracheal intubation is an essential part of resuscitation. ${ }^{12}$ It has been suggested that techniques such as bag and mask ventilation ${ }^{19}$ and laryngeal masks ${ }^{17}$ would suffice in the emergency situation, however these suggestions have been legitimately refuted.

Iserson, the most vocal proponent for ETI practice on cadavers, states that "society trusts the emergency physician will perform lifesaving interventions with the maximum possible proficiency" and that "to do otherwise invalidates this trust" ${ }^{20}$ and a number of other authors support Iserson's views. ${ }^{21} 22$ Opponents of the practice accept that both learning ETI and being proficient prior to the need are important. ${ }^{23}$ The argument therefore is not regarding the importance of ETI but whether it should be practised on cadavers, and, if so, what consent is required.

The case for practising ETI on cadavers is backed by many influential authorities. The chairman of 
The Academic Affairs Committee of the American College of Emergency Physicians claims cadaver practice of ETI is necessary or we do "our entire society a disservice". The American Heart Association's representatives state that "this practice is ethically justifiable in that it is non-mutilating, brief, beneficial to others and an effective teaching technique". 1124 Landwirth, when discussing ethical issues in paediatric and neonatal resuscitations, says "practising non-invasive or minimally invasive procedures on the newly dead is acceptable because it serves an important public and institutional need and violates no interests of the dead patient."25

Alternatives to practising ETI on cadavers do exist. Virtual reality techniques are not yet practi$\mathrm{cal}^{20}$ and animals models have disparate anatomy. ${ }^{6}$ Mannequins are considered by many to be too different anatomically, too constant anatomically and too rigid to be of use beyond the initial training. One study of mannequin use by paramedics suggested that those who trained on mannequins alone were as proficient as those who trained on mannequins and cadavers. ${ }^{26}$ If mannequin training is as good as cadaver training then the debate would become unbalanced and the process of ETI practice using cadavers should cease. However, this study has been criticised $^{27}$ and two further studies support the common perception that training using cadavers is superior. ${ }^{28} 29$

Delaying the pronouncement of death during resuscitation in order to teach or practise procedures is said to be a common event and has been described as a "deceitful and harmful hypocrisy". ${ }^{10}$

\section{Further concerns}

Practising intubation on patients undergoing anaesthesia, as suggested by the representatives of the British Medical Association ${ }^{17}$, raises further concerns. It is often performed without the patient's consent and it has the potential for injury, and possibly death. Even if consent is obtained the potential for harm remains and it has been suggested that patients prior to anaesthesia would be prone to coercion when consent is sought. ${ }^{30}$

If we accept that ETI is important and that ETI training using cadavers is better than the alternatives then we must be able to argue our right to use cadavers in this way. The arguments stated in the literature centre around altruism, communitarianism and utilitarianism.

Iserson argues the "pervasive altruism" of most people and that seeking consent from relatives contravenes the patient's altruism. ${ }^{5}$ Those who counter Iserson's argument concede that many would consent but a significant minority would not. ${ }^{40}$ Although consenting might be virtuous the commendable virtue of altruism is weakened when there is no choice.

The communitarian ethic implies both a desire and an obligation to consent as a consequence of being a member of the community and of utilizing the community's emergency services. ${ }^{20}$ Iserson continues the communitarian argument by claiming: that it represents a most egalitarian system, with anyo? member of the community providing practice ando therefore benefiting any other member of the com-을 munity who may next need intubation. ${ }^{620}$ Although $\frac{\bar{\rho}}{\frac{5}{}}$ the communitarian argument may represent "a most $\stackrel{\Phi}{\Phi}$ egalitarian" system it cannot guarantee that someo would not be intubated more than others. For example, the elderly are likely to be over-represented ${ }_{-}^{\circ}$ in unsuccessful resuscitations and therefore may $\vec{\omega}$ provide most of the practice for the community's benefit. Also there may be those to whom this represents a greater abhorrence than the average member ${ }_{N}^{\mathbb{D}}$ of the community. For example Muslims maye consider postmortem ETI to be highly objectionable and will therefore suffer a greater harm from it than others in the community who object less.

The communitarian argument, however, expounds the individual's responsibility to his or herO community whereas the utilitarian argues for the $+{ }_{0}$ greater good of the community, even if it is at the individual's expense. Iserson says that "while? societies should respect their dead, the living shoulde never be sacrificed to their memory". ${ }^{20}$

In Willard Gaylin's article "Harvesting Dead"31 he describes a future world where the desis are maintained and put to a variety of important medical uses so innovative and useful that he brings® out the utilitarian in all of us. However, after $\frac{\mathbb{Q}}{\Omega}$ describing all of the benefits of his new world he asks $\overrightarrow{\vec{A}}$ "how are we to reconcile our emotions? Where ... 을 are we to weigh . . . the repugnance generated by the entire philanthropic endeavour?"

The arguments for ETI practice on the newly dead are persuasive and well supported. The pro- $\bar{\varsigma}$ cedure is non-invasive by Iserson's definition ${ }^{10}$ (ito leaves no mark), it should be performed only on those with a cardiorespiratory death (to avoidô possible mistakes in those presumed to be brain ${ }^{2}$ dead in the emergency department) ${ }^{10}$ and it has wello argued and well accepted benefits. However, there $>$ are two striking counterarguments. The issue of the patient's desire, or obligation to consent has been N alluded to and will be discussed further in the section, About consent. The issue raised by Willardo Gaylin, of the "repugnance generated" will be dis- N cussed in the following section, About the body.

\section{About the body}

Leon Kass, after interviewing medical students recently exposed to dissection of cadavers, relateso that "they understood and felt that they weres? engaged in something fundamentally disrespectful $\mathbb{\mathbb { D }}$ albeit in a good cause". ${ }^{32}$ In $25 \%$ of departmentso that allow ETI on cadavers objection had been registered by the staff with concern that the procedure 
was disrespectful. ${ }^{30}$ However, Iserson argues that performing postmortem practice on the body is the "ultimate respect for the corpse" given the likely altruism of the erstwhile person. Furthermore, he contends, corpses are "non-persons", and merely symbols of the former person, now deceased, and as such they have no autonomy, therefore suggesting that harm can be done to them is a "legal and ethical fiction". ${ }^{20}$

\section{Profound link}

William F May explains the symbolic nature of the corpse and contends that elements of aversion and horror are a consequence of the symbolism, and with this comes an aversion to any and all who would interfere with the corpse. $^{33}$ Furthermore, the Christian tradition affirms a profound link and identity of the spirit with its somatic existence and would not readily allow invasion of the body, without explicit consent. ${ }^{34}$ These sentiments are stronger in Judaism and stronger still in Islam. The Judaeo-Christian view of the body and spirit offers a further explanation of the repugnance of tampering with the corpse, which I will call the "theory of the spiritual witness". Although it may be conceded that the person has gone from the corpse, the JudaeoChristian belief suggests that the person is still there somewhere, and that furthermore, that person, or the spirit of the person, may well be in a panoptic position and able to witness any indignities inflicted upon the corpse. Both the concern that the spirit might take offence, and the fear that there may be spiritual repercussions further fuel the feeling of repugnance.

Joel Feinberg cautions us in our respect for symbols: "A newly dead body is a sacred symbol of a real person", he says "but to respect that symbol by banning autopsies and research on cadavers is to deprive living beings of the benefit of medical knowledge." "What is called for", he continues, "is a careful rational superintendency of the sentiments". 34

It seems, therefore, that concerns of disrespect, or feeling repugnance towards procedures on the deceased are real and that their origins can be illuminated. What is argued by Feinberg and others is that those feelings should be suitably restrained when the procedures procure great benefit.

What remains to be elucidated are what rights, if any, the corpse has and what rights others have to the corpse.

The so called "no property" rule has its origins in the 13th century and suggests that the dead body does not have an owner and is not the subject of property, although the person who is charged with disposal of the corpse has a right to possession of the corpse for that purpose. ${ }^{35}$ This "quasi-property" right usually applies to the family and is the basis for suggesting the family must give consent for medical procedures on the corpse. Furthermore the coroner has a prior right to possession of the body when it is required for the purpose of coronial inquiries. The Anatomy Act of 1984 and the Human Tissue Act of 1961 define the medical research and educational activities that can be performed on cadavers in the United Kingom, however, Skegg argues that performing unauthorized postmortem procedures would be unlikely to be proven as a crime under these acts, or other statute or common law precedents. ${ }^{36}$

Goldblatt, however, argues that quasi-property rights give the family fundamental rights to the body and that using a corpse without statutory authorization or proxy consent violates the common law. ${ }^{4}$ Iserson counters that quasi-property rights apply only to ensuring an adequate burial and not to the right to refuse postmortem procedures. ${ }^{6}$ A legal precedent has not been established for ETI of cadavers and common law outcomes regarding unauthorized corneal graft harvesting and autopsies have been variable but at times they have come down in favour of the quasi-property rights of the family. ${ }^{23} 37$

In summary the corpse appears to have no legal standing but the family are afforded quasi-property rights which may extend beyond ownership for burial purposes.

Given the proven and appreciated repugnance for practising ETI on cadavers and the possibility of legal liability, should we be thinking about getting consent?

\section{About consent}

Despite the impression that usually consent is not sought the "no-consent" option is not argued in the literature but instead proponents of the procedure justify it on the basis of alternative forms of consent rather than none at all.

Implied consent describes consent that is implicit in the fact that the patient used the emergency services and it has been argued that therefore the patient is agreeable to all that entails, including being used for teaching. Implied consent criteria are commonly used for those who present, of their own volition for non-invasive medical care. However, patients who die in the emergency department most often do not present of their own volition but instead are brought in by others, usually ambulance staff, in a state of impaired autonomy. Furthermore, implied consent confers the right to administer that treatment the patient would reasonably expect at the time of presentation. In the emergency resuscitation scenario consent is also implied by the urgency and benefit of the treatment, neither of which apply to the scenario once resuscitation has ceased. Therefore if a patient's attendance is non-voluntary with impaired autonomy or with ignorance of the procedure and with no direct benefit to the patient 
then he or she cannot imply consent and we cannot infer it.

Construed consent is a modification of implied consent, suggesting that if consent was obtained for a procedure then it could be construed for a related procedure. ${ }^{4}$ If we concede that a form of consent (presumed consent - below) is obtained to intubate a patient during resuscitation, can we construe that consent also applies to ETI after death? There is an apparent logic to this as to perform the same procedure on the same patient with the same equipment one minute before and one minute after death seems a continuum of the same therapeutic relationship. However, on close analysis there is a difference sufficiently significant to render a previous consent null and void. The consent to resuscitate is based on a contract, between medical staff and patient, dedicated to helping the patient. When the objective is no longer to help the patient then the previous contract is irrelevant and a new contract must be entered into. To proceed to intubate the deceased under the old contract is a violation of the trust inherent in the previously formed therapeutic relationship and an appreciation of this violation contributes to the repugnance of the procedure.

\section{Presumed consent}

Presumed consent is appropriate when impaired autonomy renders the patient incompetent to give informed consent. Consent can be presumed, if based on a balance of beneficence over maleficence, this patient, or another reasonable person would consent in the same circumstances, if he or she were able to. In English law a "reasonable doctor standard" rather than a "reasonable person standard" of consent is employed. That is, consent can be presumed if a reasonable doctor, considering benefit and harm, and using accepted treatments, would also manage the patient in the way intended. Many common resuscitation endeavours proceed on the basis of presumed consent.

Presumed consent therefore is an extraction of the arguments already outlined of altruism, communitarianism and utilitarianism. Although it is likely that most would consent (if they could) presumed consent does disadvantage the minority who would not. ${ }^{30}$ Formal application of a presumed consent rule for ETI of the recently dead mandates that the community should be well informed so that individuals have the opportunity explicitly to decline consent if they so desire. A number of countries have presumed consent laws for organ harvesting for transplantation, meaning that all deceased are eligible for organ harvesting unless they or their families specifically decline. The relevance of this model to the question of ETI of the newly dead is significant, and will be explored later in this paper.

Proxy consent recognises the quasi-property rights of the family. Goldblatt argues that at least in the United States of America, proxy consenin authorising the medical use of a dead body is a lega芦. and ethical necessity. ${ }^{4}$ Precedent also supports the? need for proxy consent. With the exception of coronial autopsies, which are covered by statute? permission for autopsy needs to be granted by the family. Similarly, organ harvesting requires the family's consent, except in countries where explicis presumed consent is written in statutes. Orlowsk and Iserson outline the difficulties of proxy consent. ${ }^{1020}$ Relatives tend to be protective of the newly dead and therefore under-represent the patient's wishes. By the time the family are availables the body is often prepared for viewing, the resuscita tors have gone on to other pressing matters, and the body may have been transferred to the morgue. If the procedure is not performed within three to fouiv hours of death, that is, before the onset of rigoto mortis, then it loses its value. Furthermore, giving and receiving the news of the death is difficult anct then to proceed to ask permission to practise resus $=$ citation techniques on the body is considered bxh many to be an example of extreme insensitivity Furthermore, relatives may be expected to receive the request to perform ETI less favourably than \& request for organ donation as the procedure is un familiar to them and organ donation allows the per:ception that a part of their loved one "lives of "? whereas ETI offers no such incentive. Research on efforts to seek proxy consent for postmortem pro cedures reports a positive response from familo members between half and three quarters of the time. ${ }^{38} 39$ Iserson contends however, that "families should not be permitted to thwart what could reasonably have been expected to have been the deceased patient's best wishes." ${ }^{5}$ Furthermore, he. contends that requiring consent guarantees that the procedure will not be performed as most will not ask. ${ }^{6}$ Perkins and colleagues who, after extensive deliberations, introduced a proxy consent policy at. their hospital, noted that, the new policy "has hac the unintended effect of ... significantly stifling this important training." 23

\section{What should we do?}

1. STop?

Norway and Great Britain have taken this option although the British Medical Association has proposed that performing the procedure on cadavers with facial injuries is justified. Endotracheal intubac tion is undoubtably a valuable skill to learn an $\$$ practise and currently cadavers offer the best way of learning and practising, although lesser alternatives do exist.

\section{DON'T ASK, DON'T TELL?}

The President's Commission for the study of ethicak problems in medicine and biomedical and health research states that we should make "a reasonable 
effort to obtain specific consent from the next of kin when the research is beyond the normal scope of teaching and research ..." ${ }^{30}$ Although this has been used to justify a "don't ask, don't tell" approach to ETI on cadavers it cannot be considered to be within "the normal scope of teaching" if the public are oblivious to it, many find it repugnant, and two countries have banned it. If we presume consent, and don't ask, we are obliged to tell. In so doing the significant minority who would not consent are protected by an opportunity to decline. To proceed with presumed consent therefore, we must have a wellinformed public and preferably statute to formalise their consent.

\section{PROXY CONSENT?}

If we cannot proceed without consent, and we cannot presume consent without a well-informed public, and the patient has not already given us consent then proxy consent is the remaining option. Furthermore there is probably some weak common law precedent to suggest that the family's quasiproperty rights to the body demand their consent. However, as Iserson has rightly suggested, proxy consent is likely to prove such a barrier that this valuable procedure will not be performed.

\section{PRIOR CONSENT FROM THE DECEASED?}

Gaining prior consent from a terminally ill patient is a reasonable but impractical solution to this problem. However, there are two further methods of prior consent which may offer better solutions.

According to a "Guttman scale", which suggests that if an extreme procedure is accepted then all of the less extreme procedures on the scale will also be accepted, then consent for postmortem ETI might be assumed if the patient has already consented to something more extreme. ${ }^{40}$ Sanner performed a survey of public attitudes to autopsy, organ donation, and anatomic dissection and found that these procedures could be placed on a "Guttman scale" according to the procedure's "provocation of discomfort", with the ranking: autopsy, organ donation, anatomical dissection, in order of increasing provocation of discomfort. ${ }^{40}$

Endotracheal intubation on cadavers was not discussed by Sanner, nor has it been ranked on a Guttman scale and it could be proposed to be either less or more repugnant than organ donation or autopsy on such a scale. However, if the public were well informed of its benefit and its harm it would seem reasonable to assume that it would fall on a scale below autopsy or organ donation. Thus it might be inferred that a patient who has already consented to organ donation (for example by indication on his or her driver's licence, as already occurs in a number of countries) would also consent to postmortem ETI. Further research on the position of postmortem ETI on a Guttman scale is required to support any such inference.
Finally, the most convincing solution to this problem is what Spital calls "mandated choice." 30 Spital proposes a process whereby, as a matter of public policy, individuals must make choices on a variety of issues. Spital specifically discusses organ donation and such mandated choice occurs in a number of countries already with recording of the choice on, for example, the individual's driver's licence. This process informs and honours individual choice, it gives the significant minority the opportunity to decline and it avoids deception.

\section{Summary}

Endotracheal intubation is a valuable procedure which must be learnt and practised and performing ETI on cadavers is probably the best way to do this, although lesser alternatives do exist.

Performing ETI on a cadaver is viewed with a real and reasonable repugnance and if it is done without proper authorisation it might be illegal. Some form of consent is required. Presumed consent would preferably be governed by statute and should only occur if the community is well informed and therefore individuals are in a position of being able to decline. Currently neither statute nor adequate informing exists. Endotracheal intubation on the newly dead may be justifiable according to a Guttman scale if the patient has already consented to organ donation and if further research supports the relevance of the Guttman scale to this question. A "mandated choice" with prior individual consent as a matter of public policy is the best of these solutions, however until such a solution is in place we may not practise endotracheal intubation on the newly dead.

Michael Ardagh, MBChB, DCH, FACEM, is Senior Lecturer in Emergency Medicine, Christchurch School of Medicine, Christchurch, New Zealand.

\section{References}

1 Standards and guidelines for cardiopulmonary resuscitation (CPR) and emergency cardiac care (ECC). fournal of the American Medical Association 1986; 255: 2905-89.

2 Trauma Committee, Royal Australian College of Surgeons. Early management of severe trauma (EMST) course manual. Royal Australian College of Surgeons, Victoria, Australia: 1992: 31.

3 Ardagh MW. Detection of inadvertent oesophageal intubation. Emergency Medicine 1996; 8: 117-8.

4 Goldblatt AD. Don't ask, don't tell: practising minimally invasive resuscitation techniques on the newly dead. Annals of Emergency Medicine 1995; 25: 86-90.

5 Iserson KV. Requiring consent to practise and teach using the recently dead. The fournal of Emergency Medicine 1991; 9: 509-10.

6 Iserson KV. Law versus life: The ethical imperative to practise and teach using the newly dead emergency department patient. Annals of Emergency Medicine 1995; 25: 91-4. 
7 Stewart RD et al. Effect of varied training techniques on field endotracheal intubation success rates. Annals of Emergency Medicine 1984; 13: 1032-6.

$8 \mathrm{McPherson} \mathrm{JB}$. Instruction of emergency invasive procedures utilising human cadavers [abstract]. Annals of Emergency Medicine 1993; 22,5: 908.

9 Thomas HA, Jr. Using the newly dead to practise procedures in the emergency department. Newsletter of the Academic Affairs Committee of the American College of Emergency Physicians 1992 Aug 1.

10 Iserson KV. Post-mortem procedures in the emergency department: using the recently dead to practise and teach. Fournal of Medical Ethics 1993; 19: 92-8.

11 Crawford $T$. Intubation training seems mysterious. Physician Executive 1987; 13: 25-6.

12 Morhaim DK, Heller MB. The practice of teaching endotracheal intubation on recently deceased patients. The fournal of Emergency Medicine 1991; 9: 515-8.

13 Burns JP, Reardon FE, Truog RD. Using newly deceased patients to teach resuscitation procedures. New England fournal of Medicine 1994; 331,24: 1652-5.

14 Ginifer C. Teaching resuscitation skills using the newly deceased. Abstracts of the Annual Scientific Meeting of the Australasian College of Emergency Medicine and Australian Society for Emergency Medicine, 1995. Emergency Medicine 1995; 7: 241.

15 Orlowski JP, Kanoti GA, Mehlman MJ. The ethics of using newly dead patients for teaching and practising intubation techniques. New England fournal of Medicine 1988; 319: 439-41.

16 Brattebo G, Wisborg T, Solheim K, Oyen K. Public opinion on different approaches to teaching intubation techniques. British Medical fournal 1993; 307: 1256-7.

17 Tonks A. Intubation practice on cadavers should stop. British Medical fournal 1992; 305: 332.

18 Kolata G. Hospitals use bodies of dead for practice. New York Times 1994 Dec 15: A22.

19 Matz R. Practising intubation on the newly dead [letter]. New England fournal of Medicine 1989; 320,6: 396.

20 Iserson KV. Life versus death: exposing a misapplication of ethical reasoning. The fournal of Clinical Ethics 1994; 5,3: 261-4.

21 Orlowski JP. Politically correct ethical thinking and intubation practice on cadavers. The fournal of Clinical Ethics 1994; 5,3: 256-60.

22 Knopp R. Bioethics and health policy section: pactising procedures on the newly dead. Annals of Emergency Medicine 1995; 25: 99-100.

23 Perkins HS, Gordon AM. Should hospital policy require consent for practising invasive procedures on cadavers? The arguments, conclusions and lessons from one ethics committee's deliberations. The fournal of Clinical Ethics 1994; 5,3: 204-10.

24 Emergency Cardiac Care Committee and
Sub-committees: American Heart Association Guidelines for cardiopulmonary resuscitation an emergency cardiac care. The ethics of practising into bation skills. Fournal of the American Medic Association 1992; 268,16: 2286.

25 Landwirth J. Ethical issues in paediatric and neonata resuscitation. The ethics of practising intubation and ventilation skills. Annals of Emergency Medicine 19 $\overline{\overline{6}}$ 22,2: 505

26 Stratton JJ, Kane G, Gunter C et al. Retrospective study of mannequin only versus mannequins and human subject endotracheal intubation training of paramedics. Annals of Emergency Medicine 1991; 20. 1314-8.

27 Hauswold $M$. Adequate training for endotracheal int黑 bation [letter]. Annals of Emergency Medicine 199 21,9: 1168 .

28 McPherson JB. Instruction of emergency invasive pros cedures utilising human cadavers [abstract]. Annals $\$$ Emergency Medicine 1993; 22,5: 908.

29 Stewart RD et al. Effect of varied training techniques of field endotracheal intubation success rates. Annals of Emergency Medicine 1984; 13: 1032-6.

30 Hayes GJ. Issues of consent. The use of the recentI deceased for endotracheal intubation training. TT fournal of Clinical Ethics 1994; 5,3: 211-6.

31 Gaylin W. Harvesting the dead. Harper's Magazine 1974 Sept.

32 Kass LR. Thinking about the body. The Hastings Cgrte Report 1985; Feb: 20-30.

33 May WF. Religious justifications for donating bod parts. The Hastings Center Report 1985; 15: 38-42.

34 Feinberg J. The mistreatment of dead bodies. The Hastings Centre Report 985; 15: 31-7.

35 Skegg PDG.Medical uses of corpses and the 'n property' rule. Medical Science and Law 1992; 32, 311-8.

36 Skegg PDG. Criminal liability for the unauthorised use of corpses for medical education and research. Medica Science and Law 1992; 32,1: 51-4.

37 Fernandes MB. Practice of procedures on the new dead [letter]. Annals of Emergency Medicine 1995; 26, $\mathbb{R}_{\text {. }}$ 106-7.

38 Benfield DG, Flaksman RJ, Lin TH et al. Teaching intubation skills using newly deceased infanto fournal of the American Medical Association 1991; 263 2360-3.

39 McNamera RM, Monti S, Kelly JJ. Requesting conseng for an invasive procedure in newly deceased adulte fournal of the American Medical Assocation 1995; 273, 霖 310-12.

40 Sanner M. A comparison of public attitudes towards autopsy, organ donation and anatomic dissection. \& Swedish survey. Fournal of the American Medickd Association 1994; 271,4: 284-8. 